\title{
Identification of target genes in neuroinflammation and neurodegeneration after traumatic brain injury
}

\author{
Jianwei Zhao ${ }^{1}$, Chen Xu ${ }^{1}$, Heli Cao ${ }^{1}$, Lin Zhang ${ }^{1}$, Xuyang Wang ${ }^{1}$, Shiwen Chen ${ }^{\text {Corresp. } 1}$ \\ ${ }^{1}$ Department of Neurosurgery, Shanghai Jiao Tong University Affiliated Sixth People's Hospital, Shanghai, Shanghai, China \\ Corresponding Author: Shiwen Chen \\ Email address: chenshiwen@126.com
}

Background. Traumatic brain injury (TBI) is a common neurological emergency observed in hospitals. A considerable number of patients suffer from long-term disabilities after TBI. This study aimed to identify altered gene expression signatures and mechanisms related to TBI-induced chronic neuroinflammation and neurodegeneration. Methods. An integrated analysis was performed using published RNA-sequencing studies to determine TBI-induced differentially expressed genes (DEGs). Based on the DEG data, functional annotation, signal-net, and transcription factor analyses were conducted to understand the mechanism of chronic neuroinflammation and neurodegeneration induced after TBI.

Results. Two datasets were obtained using the Gene Expression Omnibus database, of which, 6513 DEGs were identified (6464 upregulated and 49 downregulated). Positive regulation of biological process, positive regulation of cellular process, nucleus, and heterocyclic compound binding were Gene Ontology terms significantly enriched in postTBI rat models. Leukocyte transendothelial migration, chemokine signaling pathway, neurotrophin signaling pathway, and longevity-regulating pathway were significantly enriched after TBI. With regard to the signal-net analysis, FOXO3, DGKZ, and ILK were considered the most critical genes derived using high-betweenness centrality calculation. A total of 44 TFs, including FOXO1, SRY, and KLF4, were predicted to play an important role in the upregulation of gene expression. Using integrated bioinformatics analysis, TBI was found to be associated with a significant inflammatory response and neurodegeneration. FOXO3, apolipoprotein $(A P O E)$, microtubule-associated protein tau (MAPT), and TREM2 were probably associated with the TBI pathological process. The mitochondrial electron transport chain may be associated with neurodegeneration in patients with TBI, serving as a potential therapeutic target. 
1 Identification of target genes in neuroinflammation and neurodegeneration after traumatic

2 brain injury

3 Running title: TBI pathological process

4 Jianwei Zhao, Chen Xu, Heli Cao, Lin Zhang, Xuyang Wang, Shiwen Chen*

5 Department of Neurosurgery, Shanghai Jiao Tong University Affiliated Sixth People's Hospital,

6 Shanghai, China

7 Corresponding Author:

8 Shiwen Chen

9 Department of Neurosurgery, Shanghai Jiao Tong University Affiliated Sixth People’s Hospital,

10 Shanghai, China

11 E-mail address: chenshiwen@126.com

\section{Abstract}

14 Background. Traumatic brain injury (TBI) is a common neurological emergency observed in

15 hospitals. A considerable number of patients suffer from long-term disabilities after TBI. This

16 study aimed to identify altered gene expression signatures and mechanisms related to TBI-

17 induced chronic neuroinflammation and neurodegeneration.

18 Methods. An integrated analysis was performed using published RNA-sequencing studies to 
19 determine TBI-induced differentially expressed genes (DEGs). Based on the DEG data,

20 functional annotation, signal-net, and transcription factor analyses were conducted to understand

21 the mechanism of chronic neuroinflammation and neurodegeneration induced after TBI.

22 Results. Two datasets were obtained using the Gene Expression Omnibus database, of which,

236513 DEGs were identified (6464 upregulated and 49 downregulated). Positive regulation of

24 biological process, positive regulation of cellular process, nucleus, and heterocyclic compound

25 binding were Gene Ontology terms significantly enriched in post-TBI rat models. Leukocyte

26 transendothelial migration, chemokine signaling pathway, neurotrophin signaling pathway, and

27 longevity-regulating pathway were significantly enriched after TBI. With regard to the signal-net

28 analysis, FOXO3, DGKZ, and ILK were considered the most critical genes derived using high-

29 betweenness centrality calculation. A total of 44 TFs, including FOXO1, SRY, and KLF4, were

30 predicted to play an important role in the upregulation of gene expression. Using integrated

31 bioinformatics analysis, TBI was found to be associated with a significant inflammatory

32 response and neurodegeneration. FOXO3, apolipoprotein (APOE), microtubule-associated

33 protein tau $(M A P T)$, and TREM2 were probably associated with the TBI pathological process.

34 The mitochondrial electron transport chain may be associated with neurodegeneration in patients

35 with TBI, serving as a potential therapeutic target.

36 Key words Bioinformatics; integrated analysis; neurodegeneration; neuroinflammation;

37 traumatic brain injury 


\section{Introduction}

40 More than 50 million people worldwide suffer from traumatic brain injury (TBI) each year.

41 Astonishingly, about half of the world's population may encounter one or more brain injuries in

42 their lifetime (Maas et al. 2017). Based on the World Health Organization estimate, TBI will be

43 the third leading cause of death and disability by the year 2020

44 (https://www.thelancet.com/pdfs/journals/laneur/PIIS1474-4422(12)70166-7.pdf, 2012). Patients

45 who survive TBI most likely suffer from disabilities, including cognitive, motor, and emotional

46 deficits. This has a substantial impact on the health care industry, patients' families, and society

47 (Puntambekar et al. 2018).

48 Resident microglia and peripheral macrophages induce inflammation of the central nervous

49 system (CNS) after TBI (Russo \& McGavern 2016). Immune-mediated neuroinflammation can

50 persist for several years after a single brain injury (McKee \& Lukens 2016; Ramlackhansingh et

51 al. 2011). Increasing experimental evidence has demonstrated that the neuroinflammatory system

52 can significantly influence clinical prognosis following TBI. Furthermore, TBI-induced

53 inflammation and pathology have been strongly associated with increased risks of

54 neurodegenerative diseases such as chronic traumatic encephalopathy, Alzheimer's disease (AD),

55 and Parkinson's disease (PD) (Goldman et al. 2006; McKee et al. 2009; Mortimer et al. 1991).

56 Numerous epidemiological studies on patients with post-TBI dementia have supported the

57 association between TBI and AD (Nordstrom et al. 2014; Plassman et al. 2000). An

58 understanding of the disease mechanism that results in long-term disabilities after TBI is 
59 urgently needed.

60 An integrated transcriptome analysis was performed in this study using samples from chronic

61 stages of TBI to eliminate transcriptomic changes associated with acute TBI post-injury. Using

62 bioinformatics methods, this study aimed to identify key gene expression changes, pathways, and

63 transcription factors (TFs) associated with chronic changes after TBI. In addition, a signal-net

64 map was constructed to determine key gene interactions. Among the differentially expressed

65 genes (DEGs), genes related to neurodegenerative diseases, especially $\mathrm{AD}$, and

66 neuroinflammation-related genes were the major focus. Besides, apoptosis and autophagy have

67 been widely investigated in TBI and neurodegenerative disorder models (Ghavami et al. 2014;

68 Zhang et al. 2016). This study also explored whether apoptosis and autophagy play a role in the

69 chronic process of brain injury. It described selected genes and pathways relevant to

70 neurodegenerative and neuroinflammation conditions and might provide insights into

71 understanding TBI-induced disabilities.

72

\section{Materials and Methods}

74 Selection of relevant sequencing data for TBI transcriptomics analysis

75 The Gene Expression Omnibus (GEO) database (http:/www.ncbi.nlm.nih.gov/geo) from the

76 National Center of Biotechnology Information (NCBI) was searched for relevant sequencing

77 datasets for TBI. Datasets were selected based on the following criteria: the samples analyzed 
78 were from the hippocampus tissue of Sprague-Dawley (SD) rats and RNA sequencing was

79 performed 3 months after TBI. Two independent reviewers extracted the data from the original

80 published studies. The following data were extracted from each study: GEO accession number,

81 platform, number of rats in the TBI and normal control (NC) groups, and gene expression data.

\section{Identification of DEGs}

83 The raw data of selected studies were obtained from the NCBI-SRA database

84 (https://www.ncbi.nlm.nih.gov/sra/). The HISAT2(http://ccb.jhu.edu/software/hisat2,v2 2.1.0)

85 was used to align the RNA-seq data and StringTie (http://ccb.jhu.edu/software/stringtie,v1.3.5)

86 to assemble and quantify the transcripts (Pertea et al. 2016). R statistical software

87 (https://www.r-project.org/, v3.4.4) and Bioconductor package helped visualize the results. The

88 datasets were then assigned into two groups: exp (TBI) group and con (control) group. The

89 DEGs between the TBI hippocampus tissue and control tissue were analyzed using the classical $t$

90 test (stats package, version 3.4.4) in R [settings: $P<0.05$; false discovery rate $(\mathrm{FDR})<0.05$; fold

91 change $(\mathrm{FC})>1.2$; or fold change $<0.833$ ]. A heat map for top 50 DEGs was produced using the

92 "pheatmap" package (version 1.0.10) of R. A principal component analysis (PCA) plot was

93 conducted to determine the principal components using the DEG list and visualized using the

94 “ggbiplot2” R package.

95 Functional and pathway enrichment analysis of the DEGs

96 Functional terms were retrieved from the Gene Ontology (GO) database. The analyses were

97 performed using the Fisher's exact test and multiple comparison test, with a $P$ value $<0.05$ set as 
98 the cutoff criteria. A pathway analysis was performed to identify significantly different

99 regulatory pathways using the Kyoto Encyclopedia of Genes and Genomes (KEGG). Fisher's

100 exact test and $\chi^{2}$ test were used to select significantly enriched pathways. GO and KEGG

101 analyses were performed using the clusterProfiler package (http://bioconductor.org/biocLite.R,

102 version 3.10.1) of R statistical software.

\section{Signal-net analysis}

104 The KEGG database was used to analyze functional gene interactions (Schlitt et al. 2003) and 105 gene signal transduction network (signal-net) (Zhang et al. 2017) to analyze the connectivity of 106 DEGs and their potential role in TBI. Intergenic connections between upstream and downstream 107 genes included activation, phosphorylation, binding, compound, and dephosphorylation. Within 108 the signal-net map, nodes indicated genes and edges indicated relationship types between the

109 DEGs. The significance of a gene in the network was evaluated by measuring its "between 110 centrality." "Between centrality" represented the mediating capacity of each gene, that is, the 111 number of times a node was located on the shortest path between two other nodes. Hence, the

112 higher the between centrality score for a gene, the greater its significance in the signal-net map.

113 The Cytoscape (3.7.2) software was used to generate the signal-net analysis map.

115 Identification of TFs

116 Further, $2000 \mathrm{bp}$ upstream and $500 \mathrm{bp}$ downstream from the transcription start site (TSS) of each 
117 DEG was analyzed for TF binding sites. Based on the Match algorithm, the TRANSFAC

118 database was used to predict possible TF binding sites adjacent to the TSS. Prediction results

119 were evaluated using core and matrix scores. Core match referred to five conserved bases of the

120 binding region between the TF and the promoter, which were indicated with capital letters.

121 Matching score indicated the accuracy of prediction results. Higher values indicated higher

122 precise prediction results. Matrix scores indicated the accuracy of prediction results, with higher

123 scores indicating higher precise prediction results. The integrated analysis predicted the TFs of

124 selected genes associated with neurodegeneration and inflammation. Besides, the network map

125 of mRNA-TF was constructed using the Cytoscape (3.7.2) software.

126

127 Results

128 Selection of sequencing datasets for TBI transcriptome analysis

129 The gene expression profiles of GSE75120 (Debski et al. 2016) and GSE80174 (Lipponen et al.

130 2016) included $10 \mathrm{TBI}$ and $10 \mathrm{NC}$ samples. These two sequencing datasets provided gene

131 expression profiles of the hippocampus tissue of male SD rats. TBI was induced using the lateral

132 fluid percussion (LFP) method. The hippocampal tissue was profiled 3 months after LFP-

133 induced TBI with corresponding sham-treated controls. High-throughput sequencing was

134 performed for the two studies using the Illumina Genome Analyzer IIx (Rattus norvegicus) 135 platform. 


\section{Identification of DEGs}

137 A total of 6513 genes were identified to be differentially expressed between TBI and the NC

138 group; of these, 6464 were upregulated and 49 were downregulated $(P<0.05$, FDR $<0.05$ and

$139 \mathrm{FC}>1.2$ or $\mathrm{FC}<0.833$ ). The normalized raw data and DEG data files are available in

140 supplemental files. A PCA plot was drawn to assess the variability of data. The PC1 and PC2

141 explained $74.6 \%$ and $5.2 \%$ of the variance in the data, respectively. Exp group was isolated from

142 the con group. For a more in-depth exploration, 20 genes were listed, including 6 hub genes

143 obtained in the signal-net analysis and 14 genes related to neurodegeneration and

144 neuroinflammation. Further, 20 genes of interest were selected (Table 1). A heat map of all the

145 DEGs is depicted in Figure 1a, whereas a PCA plot of DEGs is depicted in Figure 1b.

\section{Functional enrichment analysis for DEGS}

147 Three functional groups were classified based on the GO analysis: cellular component (CC),

148 molecular function (MF), and biological process (BP). In the MF group, heterocyclic compound

149 binding, organic cyclic compound binding, ion binding, and RNA binding were the most

150 significantly enriched GO terms (Fig. 2). With regard to CC, the most enriched GO terms were

151 nucleus, cytosol, intracellular organelle lumen, and membrane-enclosed lumen. For BP analysis,

152 DEGs were significantly enriched for the positive regulation of the biological process, positive

153 regulation of the cellular process, and $\mathrm{CC}$ organization or biogenesis. The top GO term results

154 enriched using DEGs for TBI are shown in Figure 2. After the KEGG pathway enrichment

155 analysis of the DEGs, 15 significantly enriched molecular pathways of interest were selected. 
156 These included leukocyte transendothelial migration, chemokine signaling pathway,

157 neurotrophin signaling pathway, and longevity-regulating pathway (Table 2 and Fig. 3). On

158 directly comparing the overlapping gene list from KEGG, genes that overlapped with

159 neurodegenerative brain disorders, including AD, PD, and Huntington disease, were found

160 (overlapping genes shown in Table 3).

\section{Signal-net analysis of the DEGs}

162 To further investigate gene interaction networks, the most significant gene nodes were identified

163 using the signal-net analysis based on the genes of interest. FOXO3, DGKZ, ILK, RXRA, PLCB3,

164 and CALM1 were found to be the most significant genes determined using high-betweenness

165 centrality calculation (Fig. 4).

166 TF analysis

167 A total of 20 DEGs (DEGs enriched for pathways related to neurodegeneration and

168 neuroinflammation, shown in Table 1) were used to construct the mRNA-TF-Net (Fig. 5). Based

169 on the map, 44 TFs were predicted to play an important role in the upregulation of gene

170 expression. FOXO1 and SRY (degree = 20), and KLF4, KLF6, PARP1, POU3F3, PRRX1, and

171 RUNX1 (degree $=19$ ) were the top TFs found to play a role in DEGs.

172

173 Discussion

174 An integrated analysis of high-throughput sequencing data was performed to determine the 
175 molecular mechanisms associated with TBI. Using the bioinformatics analysis, several genes,

176 pathways, and TFs associated with neuroinflammation and neurodegeneration, which might play

177 important roles in post-TBI molecular mechanisms, were identified.

178 The present study was consistent with previous studies demonstrating that TBI induced 179 neuroinflammation and neurodegeneration (Meng et al. 2017; Ransohoff 2016; Russo \& 180 McGavern 2016; Simon et al. 2017; White et al. 2013). Several genes enriched for TBI and 181 neurodegenerative diseases were identified. Apolipoprotein $(A P O E)$, an independent risk factor 182 for the development of AD, was found to be upregulated (Farrer et al. 1997; Lupton et al. 2016). 183 In addition, the microtubule-associated protein tau (MAPT) gene, a neuronal marker, was 184 significantly upregulated in the TBI group. The MAPT gene encodes the tau protein and is 185 involved in multiple neuropathologies, especially AD (Garcia-Escudero et al. 2017).

186 TREM2 has been demonstrated to be an independent risk factor for late-onset AD (Guerreiro et 187 al. 2013). The $\mathrm{R} 47 \mathrm{H}$ variant in TREM2 is associated with a significant increase in AD risk 188 (Guerreiro et al. 2013). In the present analysis, TREM2 and TYROBP (encode DAP12, an adaptor 189 that regulates signaling via TREM2) (Thrash et al. 2009) were upregulated in hippocampal 190 samples from rats with 3-month post-TBI. Furthermore, FOXO3 was found to be an important 191 gene based on high-betweenness centrality calculation after the signal-net analysis. Several 192 studies have consistently demonstrated that $A P O E$ and FOXO3 function as "longevity genes" 193 (Broer et al. 2015; Willcox et al. 2006). Deacetylation of FOXO3A has been shown to possess a 194 neuroprotective role in Huntington's disease models (Jiang et al. 2011). Besides TREM2, the 
195 expression of $A B I 3$ also increased in TBI according to the present analysis, which has been

196 considered to modulate the susceptibility to AD in recent years (Dalmasso et al. 2019). Both of

197 them are highly expressed in microglia, providing evidence for the role of a microglia-mediated

198 innate immune response in the development of AD (Sims et al. 2017).

199 The activation of microglia residing in the CNS and subsequent recruitment of peripheral 200 inflammatory macrophages play a major role in acute immune response after TBI; it lasts for 201 months to years (McKee \& Lukens 2016). Hickman et al. (Hickman et al. 2013) demonstrated 202 that both brain-resident microglia and peripheral macrophages express a unique set of genes and 203 are distinct from other cells. Several genes exclusively expressed in microglia were found with 204 significantly higher expression compared with controls. They included SLCO2B1, TMEM119, 205 P2RY12, FCGR3A, TYROBP, and TREM2. Additionally, genes exclusively expressed in 206 macrophages were also significantly upregulated after TBI and included PF4, CRIP1, and PRG4.

207 These results indicated that the chronic activation of infiltrating macrophages and resident 208 microglia were present in the hippocampus for at least 3 months after TBI.

209 Apoptosis and autophagy are the basic physiological processes to maintain brain homeostasis. In 210 the present study, the autophagy markers (SQSTM1 and MAP1LC3A) and the apoptosis marker 211 (CASP9) both increased significantly in TBI. However, the relationship between them is 212 perplexing due to the interconnected nature of both processes (Zhang et al. 2013). Hence, the 213 regulation of apoptosis and autophagy processes should be done with caution. Also, further 214 studies are needed to clarify the role of both processes in the chronic course of TBI. Axonal 
215 repair is important for the recovery of brain injury. ABCA1 is a major regulator of cellular

216 cholesterol and phospholipid homeostasis necessary for axonal restoration, which transports

217 lipids and cholesterol onto APOE (Castranio et al. 2018). Meanwhile, MAG, which is a

218 transmembrane glycoprotein localized in periaxonal cells, plays a role in the inhibition of nerve

219 regeneration after injury in the CNS (Yiu \& He 2006). In the present study, the expression of

$220 A B C A 1$ and $M A G$ both increased significantly in chronic brain injury. Related target gene

221 therapy may be effective for axonal repair in TBI.

222 Then, KEGG enrichment analysis was performed, focusing on pathways associated with

223 neurodegeneration and neuroinflammation. Neurodegenerative diseases, such as PD, AD, and

224 Huntington's disease, were not significantly enriched. However, several overlapping genes were

225 identified for these three neurodegenerative diseases. These included NADH dehydrogenase

226 (ubiquinone) subunits such as Ndufa1, Ndufa11, Ndufa12, and Ndufa6, and cytochrome c

227 oxidase subunits such as Cox4i1, Cox5a, and Cox6a1. Large protein complexes are found in the

228 electron transport chain (ETC) located in the mitochondria. TBI may induce the expression of

229 genes in the mitochondrial ETC in various brain regions (Xing et al. 2013). ETC overexpression

230 in the hippocampus has been reported to be associated with aging and increased oxidative

231 damage in mouse brains (Manczak et al. 2005), and with age-related diseases such as AD and PD

232 (Kim et al. 2000; Manczak et al. 2005). The data suggested that increased ETC expression in

233 mitochondria might be associated with poor prognoses, such as neurodegenerative disorders in

234 patients with TBI. Studies on patients with TBI and animal models have demonstrated an 
235 imbalance in immune response, which subsequently leads to neurological dysfunction and brain

236 pathology disorders (Shiozaki et al. 2005; Woiciechowsky et al. 2002). Immune-mediated

237 inflammatory responses can last for months to several years following initial injury (Jassam et al.

238 2017; Johnson et al. 2013) and result in chronic tissue damage (Puntambekar et al. 2018).

239 Leukocyte transendothelial migration, NOD-like receptor signaling pathway, and chemokine

240 signaling pathway related to the immune system were enriched after TBI. In addition, pathways

241 that might be neuroprotective, such as neurotrophin signaling pathway, autophagy pathway, and

242 longevity-regulating pathway, were also upregulated.

243 TBI-induced behavioral changes are associated with duration after primary trauma (Baratz et al.

244 2011). The data of the present study supported this observation because rats with TBI displayed

245 significant changes in gene sets associated with neuroinflammation and neurodegenerative

246 disease 3 months after TBI. TBI pathology has been demonstrated to be associated with

247 inflammation; however, currently, no consensus exists regarding whether and how it should be

248 targeted therapeutically. The relationship between neuroinflammation and neurodegenerative

249 disease is difficult to define. However, understanding the changes that occur in immunocytes,

250 such as in microglia, after TBI might provide clues on how to prevent the chronic pathological

251 process of TBI, including chronic neuroinflammation. Strategies targeting the microglia are

252 believed to be effective in inhibiting neurodegeneration. For example, an increase in the ability

253 of microglia to recognize amyloid-beta peptide $(\mathrm{A} \beta)$ and abnormal aggregation of tau filaments

254 (the cardinal features of AD) have been achieved via immunotherapy using specific antibodies 
255 (Citron 2010; Kondo et al. 2015).

256 One limitation of the present study was that the sequencing data was retrieved using whole

257 hippocampus tissues rather than purified cells. Gene expression changes observed in these 258 studies reflected a mixture of gene expression profiles (glial cells, neurons, and even possibly 259 circulating blood leukocytes). Hence, new techniques such as laser capture microdissection to 260 isolate and capture diverse cell types, are necessary to understand TBI-induced 261 neurodegenerative mechanisms.

\section{Conclusions}

264 In conclusion, the present study demonstrated that TBI was associated with significant 265 inflammatory responses and neurodegeneration. It showed that FOXO3 played a core role in 266 modulating post-BI gene networks. Several DEGs, including APOE, MAPT, and TREM2, might 267 be involved in neurodegeneration after TBI, with the participation of microglia and peripheral 268 macrophages in chronic inflammation after TBI. In addition, the data suggested that ETC 269 expression in mitochondria might be associated with neurodegeneration in patients with TBI. 270 The findings of the present study might provide novel insights into mechanisms related to the 271 chronic phase of TBI and may help develop new diagnostic and therapeutic treatments for TBI. 
274 Not applicable

\section{Funding}

276 This work was supported by the project of Shanghai Science and Technology Commission

277 (19ZR1438600).

\section{Conflict of interests}

279 All authors declare that they have no any conflict of interests.

280

281

\section{References}

282

283

284

285

286

287

288

289

290

291

292

2012. The changing landscape of traumatic brain injury research. Lancet Neurol 11:651. Doi: $10.1016 / \mathrm{s} 1474-4422(12) 70166-7$.

Online

available: https://www.thelancet.com/pdfs/journals/laneur/PIIS1474-4422(12)70166-7.pdf

Baratz R, Tweedie D, Rubovitch V, Luo W, Yoon JS, Hoffer BJ, Greig NH, and Pick CG. 2011. Tumor necrosis factor-alpha synthesis inhibitor, 3,6'-dithiothalidomide, reverses behavioral impairments induced by minimal traumatic brain injury in mice. $J$ Neurochem 118:1032-1042. Doi: 10.1111/j.1471-4159.2011.07377.x

Broer L, Buchman AS, Deelen J, Evans DS, Faul JD, Lunetta KL, Sebastiani P, Smith JA, Smith AV, Tanaka T, Yu L, Arnold AM, Aspelund T, Benjamin EJ, De Jager PL, Eirkisdottir G, Evans DA, Garcia ME, Hofman A, Kaplan RC, Kardia SL, Kiel DP, Oostra BA, Orwoll ES, Parimi N, Psaty BM, Rivadeneira F, Rotter JI, Seshadri S, Singleton A, Tiemeier H, 
Uitterlinden AG, Zhao W, Bandinelli S, Bennett DA, Ferrucci L, Gudnason V, Harris TB,

Duijn CM, and Murabito JM. 2015. GWAS of longevity in CHARGE consortium

confirms APOE and FOXO3 candidacy. J Gerontol A Biol Sci Med Sci 70:110-118. Doi:

Castranio EL, Wolfe CM, Nam KN, Letronne F, Fitz NF, Lefterov I, and Koldamova R. 2018.

ABCA1 haplodeficiency affects the brain transcriptome following traumatic brain injury

in mice expressing human APOE isoforms. Acta Neuropathol Commun 6:69. Doi:

$10.1186 / \mathrm{s} 40478-018-0569-2$

Citron M. 2010. Alzheimer's disease: strategies for disease modification. Nat Rev Drug Discov 9:387-398. Doi: 10.1038/nrd2896

Dalmasso MC, Brusco LI, Olivar N, Muchnik C, Hanses C, Milz E, Becker J, Heilmann305 Heimbach S, Hoffmann P, Prestia FA, Galeano P, Avalos MSS, Martinez LE, Carulla ME, Azurmendi PJ, Liberczuk C, Fezza C, Sampano M, Fierens M, Jemar G, Solis P, Medel N, Lisso J, Sevillano Z, Bosco P, Bossu P, Spalletta G, Galimberti D, Mancuso M, Nacmias B, Sorbi S, Mecocci P, Pilotto A, Caffarra P, Panza F, Bullido M, Clarimon J, Sanchez-Juan P, Coto E, Sanchez-Garcia F, Graff C, Ingelsson M, Bellenguez C, Castano EM, Kairiyama C, Politis DG, Kochen S, Scaro H, Maier W, Jessen F, Mangone CA, Lambert JC, Morelli L, and Ramirez A. 2019. Transethnic meta-analysis of rare coding variants in PLCG2, ABI3, and TREM2 supports their general contribution to Alzheimer's 
314

315

316

317

318

319

320

321

322

323

324

325

326

327

328

329

330

331

332

333

334

Debski KJ, Pitkanen A, Puhakka N, Bot AM, Khurana I, Harikrishnan KN, Ziemann M, Kaspi A, El-Osta A, Lukasiuk K, and Kobow K. 2016. Etiology matters - Genomic DNA Methylation Patterns in Three Rat Models of Acquired Epilepsy. Sci Rep 6:25668. Doi: $10.1038 /$ srep25668

Farrer LA, Cupples LA, Haines JL, Hyman B, Kukull WA, Mayeux R, Myers RH, PericakVance MA, Risch N, and van Duijn CM. 1997. Effects of age, sex, and ethnicity on the association between apolipoprotein E genotype and Alzheimer disease. A meta-analysis. APOE and Alzheimer Disease Meta Analysis Consortium. Jama 278:1349-1356.

Garcia-Escudero V, Gargini R, Martin-Maestro P, Garcia E, Garcia-Escudero R, and Avila J. 2017. Tau mRNA 3'UTR-to-CDS ratio is increased in Alzheimer disease. Neurosci Lett 655:101-108. Doi: 10.1016/j.neulet.2017.07.007

Ghavami S, Shojaei S, Yeganeh B, Ande SR, Jangamreddy JR, Mehrpour M, Christoffersson J, Chaabane W, Moghadam AR, Kashani HH, Hashemi M, Owji AA, and Los MJ. 2014. Autophagy and apoptosis dysfunction in neurodegenerative disorders. Prog Neurobiol 112:24-49. Doi: 10.1016/j.pneurobio.2013.10.004

Goldman SM, Tanner CM, Oakes D, Bhudhikanok GS, Gupta A, and Langston JW. 2006. Head injury and Parkinson's disease risk in twins. Ann Neurol 60:65-72. Doi: 10.1002/ana.20882

Guerreiro R, Wojtas A, Bras J, Carrasquillo M, Rogaeva E, Majounie E, Cruchaga C, Sassi C, Kauwe JS, Younkin S, Hazrati L, Collinge J, Pocock J, Lashley T, Williams J, Lambert JC, Amouyel P, Goate A, Rademakers R, Morgan K, Powell J, St George-Hyslop P, 

368:117-127. Doi: 10.1056/NEJMoa1211851

337 Hickman SE, Kingery ND, Ohsumi TK, Borowsky ML, Wang LC, Means TK, and El Khoury J. 2013. The microglial sensome revealed by direct RNA sequencing. Nat Neurosci 16:1896-1905. Doi: 10.1038/nn.3554

Jassam YN, Izzy S, Whalen M, McGavern DB, and El Khoury J. 2017. Neuroimmunology of Traumatic Brain Injury: Time for a Paradigm Shift. Neuron 95:1246-1265. Doi: 10.1016/j.neuron.2017.07.010

Jiang M, Wang J, Fu J, Du L, Jeong H, West T, Xiang L, Peng Q, Hou Z, Cai H, Seredenina T, Arbez N, Zhu S, Sommers K, Qian J, Zhang J, Mori S, Yang XW, Tamashiro KL, Aja S, Moran TH, Luthi-Carter R, Martin B, Maudsley S, Mattson MP, Cichewicz RH, Ross CA, Holtzman DM, Krainc D, and Duan W. 2011. Neuroprotective role of Sirt1 in mammalian models of Huntington's disease through activation of multiple Sirt1 targets. Nat Med 18:153-158. Doi: 10.1038/nm.2558

Johnson VE, Stewart JE, Begbie FD, Trojanowski JQ, Smith DH, and Stewart W. 2013. Inflammation and white matter degeneration persist for years after a single traumatic brain injury. Brain 136:28-42. Doi: 10.1093/brain/aws322

Kim SH, Vlkolinsky R, Cairns N, and Lubec G. 2000. Decreased levels of complex III core protein 1 and complex $\mathrm{V}$ beta chain in brains from patients with Alzheimer's disease and Down syndrome. Cell Mol Life Sci 57:1810-1816. 
Sun Y, Wei S, Luo ML, Albayram O, Huang P, Rotenberg A, Ryo A, Goldstein LE,

357

358

359

360

361

362

363

Pascual-Leone A, McKee AC, Meehan W, Zhou XZ, and Lu KP. 2015. Antibody against early driver of neurodegeneration cis P-tau blocks brain injury and tauopathy. Nature 523:431-436. Doi: 10.1038/nature14658

Lipponen A, Paananen J, Puhakka N, and Pitkanen A. 2016. Analysis of Post-Traumatic Brain Injury Gene Expression Signature Reveals Tubulins, Nfe212, Nfkb, Cd44, and S100a4 as Treatment Targets. Sci Rep 6:31570. Doi: 10.1038/srep31570

Lupton MK, Strike L, Hansell NK, Wen W, Mather KA, Armstrong NJ, Thalamuthu A, McMahon KL, de Zubicaray GI, Assareh AA, Simmons A, Proitsi P, Powell JF, Montgomery GW, Hibar DP, Westman E, Tsolaki M, Kloszewska I, Soininen H, Mecocci P, Velas B, Lovestone S, Brodaty H, Ames D, Trollor JN, Martin NG, Thompson PM, Sachdev PS, and Wright MJ. 2016. The effect of increased genetic risk for Alzheimer's disease on hippocampal and amygdala volume. Neurobiol Aging 40:6877. Doi: 10.1016/j.neurobiolaging.2015.12.023

Maas AIR, Menon DK, Adelson PD, Andelic N, Bell MJ, Belli A, Bragge P, Brazinova A, Buki A, Chesnut RM, Citerio G, Coburn M, Cooper DJ, Crowder AT, Czeiter E, Czosnyka M, Diaz-Arrastia R, Dreier JP, Duhaime AC, Ercole A, van Essen TA, Feigin VL, Gao G, Giacino J, Gonzalez-Lara LE, Gruen RL, Gupta D, Hartings JA, Hill S, Jiang JY, Ketharanathan N, Kompanje EJO, Lanyon L, Laureys S, Lecky F, Levin H, Lingsma HF, Maegele M, Majdan M, Manley G, Marsteller J, Mascia L, McFadyen C, Mondello S, Newcombe V, Palotie A, Parizel PM, Peul W, Piercy J, Polinder S, Puybasset L, 
Rasmussen TE, Rossaint R, Smielewski P, Soderberg J, Stanworth SJ, Stein MB, von and research. Lancet Neurol 16:987-1048. Doi: 10.1016/s1474-4422(17)30371-x

Manczak M, Jung Y, Park BS, Partovi D, and Reddy PH. 2005. Time-course of mitochondrial gene expressions in mice brains: implications for mitochondrial dysfunction, oxidative damage, and cytochrome c in aging. J Neurochem 92:494-504. Doi: 10.1111/j.14714159.2004.02884.X

McKee AC, Cantu RC, Nowinski CJ, Hedley-Whyte ET, Gavett BE, Budson AE, Santini VE, Lee HS, Kubilus CA, and Stern RA. 2009. Chronic traumatic encephalopathy in athletes: progressive tauopathy after repetitive head injury. J Neuropathol Exp Neurol 68:709-735. 10.1097/NEN.0b013e3181a9d503

McKee CA, and Lukens JR. 2016. Emerging Roles for the Immune System in Traumatic Brain Injury. Front Immunol 7:556. Doi: 10.3389/fimmu.2016.00556

Meng Q, Zhuang Y, Ying Z, Agrawal R, Yang X, and Gomez-Pinilla F. 2017. Traumatic Brain Injury Induces Genome-Wide Transcriptomic, Methylomic, and Network Perturbations in Brain and Blood Predicting Neurological Disorders. EBioMedicine 16:184-194. Doi: 10.1016/j.ebiom.2017.01.046 
Alzheimer's disease: a collaborative re-analysis of case-control studies. EURODEM Risk

Nordstrom P, Michaelsson K, Gustafson Y, and Nordstrom A. 2014. Traumatic brain injury and young onset dementia: a nationwide cohort study. Ann Neurol 75:374-381.

402

403

404

405

406

407

408

409

410

411

412

413

414

415

416

417

Pertea M, Kim D, Pertea GM, Leek JT, and Salzberg SL. 2016. Transcript-level expression analysis of RNA-seq experiments with HISAT, StringTie and Ballgown. Nat Protoc 11:1650-1667. Doi: 10.1038/nprot.2016.095

Plassman BL, Havlik RJ, Steffens DC, Helms MJ, Newman TN, Drosdick D, Phillips C, Gau BA, Welsh-Bohmer KA, Burke JR, Guralnik JM, and Breitner JC. 2000. Documented head injury in early adulthood and risk of Alzheimer's disease and other dementias. Neurology 55:1158-1166. Doi: 10.1212/wnl.55.8.1158

Puntambekar SS, Saber M, Lamb BT, and Kokiko-Cochran ON. 2018. Cellular players that shape evolving pathology and neurodegeneration following traumatic brain injury. Brain Behav Immun 71:9-17. Doi: 10.1016/j.bbi.2018.03.033

Ramlackhansingh AF, Brooks DJ, Greenwood RJ, Bose SK, Turkheimer FE, Kinnunen KM, Gentleman S, Heckemann RA, Gunanayagam K, Gelosa G, and Sharp DJ. 2011. Inflammation after trauma: microglial activation and traumatic brain injury. Ann Neurol 70:374-383. Doi: 10.1002/ana.22455

Ransohoff RM. 2016. How neuroinflammation contributes to neurodegeneration. Science 353:777-783. Doi: 10.1126/science.aag2590

418 Russo MV, and McGavern DB. 2016. Inflammatory neuroprotection following traumatic brain 
injury. Science 353:783-785. Doi: 10.1126/science.aaf6260

420 Schlitt T, Palin K, Rung J, Dietmann S, Lappe M, Ukkonen E, and Brazma A. 2003. From gene networks to gene function. Genome Res 13:2568-2576. Doi: 10.1101/gr.1111403

422

423

424

425

426

427

428

429

430

431

432

433

434

435

436

437

438

439

Shiozaki T, Hayakata T, Tasaki O, Hosotubo H, Fuijita K, Mouri T, Tajima G, Kajino K, Nakae H, Tanaka H, Shimazu T, and Sugimoto H. 2005. Cerebrospinal fluid concentrations of anti-inflammatory mediators in early-phase severe traumatic brain injury. Shock 23:406410.

Simon DW, McGeachy MJ, Bayir H, Clark RS, Loane DJ, and Kochanek PM. 2017. The farreaching scope of neuroinflammation after traumatic brain injury. Nat Rev Neurol 13:171-191. Doi: 10.1038/nrneurol.2017.13

Sims R, van der Lee SJ, Naj AC, Bellenguez C, Badarinarayan N, Jakobsdottir J, Kunkle BW, Boland A, Raybould R, Bis JC, Martin ER, Grenier-Boley B, Heilmann-Heimbach S, Chouraki V, Kuzma AB, Sleegers K, Vronskaya M, Ruiz A, Graham RR, Olaso R, Hoffmann P, Grove ML, Vardarajan BN, Hiltunen M, Nothen MM, White CC, HamiltonNelson KL, Epelbaum J, Maier W, Choi SH, Beecham GW, Dulary C, Herms S, Smith AV, Funk CC, Derbois C, Forstner AJ, Ahmad S, Li H, Bacq D, Harold D, Satizabal CL, Valladares O, Squassina A, Thomas R, Brody JA, Qu L, Sanchez-Juan P, Morgan T, Wolters FJ, Zhao Y, Garcia FS, Denning N, Fornage M, Malamon J, Naranjo MCD, Majounie E, Mosley TH, Dombroski B, Wallon D, Lupton MK, Dupuis J, Whitehead P, Fratiglioni L, Medway C, Jian X, Mukherjee S, Keller L, Brown K, Lin H, Cantwell LB, Panza F, McGuinness B, Moreno-Grau S, Burgess JD, Solfrizzi V, Proitsi P, Adams HH, 
Allen M, Seripa D, Pastor P, Cupples LA, Price ND, Hannequin D, Frank-Garcia A,

Levy D, Chakrabarty P, Caffarra P, Giegling I, Beiser AS, Giedraitis V, Hampel H,

Garcia ME, Wang X, Lannfelt L, Mecocci P, Eiriksdottir G, Crane PK, Pasquier F,

Boccardi V, Henandez I, Barber RC, Scherer M, Tarraga L, Adams PM, Leber M, Chen

Y, Albert MS, Riedel-Heller S, Emilsson V, Beekly D, Braae A, Schmidt R, Blacker D,

Masullo C, Schmidt H, Doody RS, Spalletta G, Longstreth WT, Jr., Fairchild TJ, Bossu P,

Lopez OL, Frosch MP, Sacchinelli E, Ghetti B, Yang Q, Huebinger RM, Jessen F, Li S,

Kamboh MI, Morris J, Sotolongo-Grau O, Katz MJ, Corcoran C, Dunstan M, Braddel A,

Thomas C, Meggy A, Marshall R, Gerrish A, Chapman J, Aguilar M, Taylor S, Hill M,

Fairen MD, Hodges A, Vellas B, Soininen H, Kloszewska I, Daniilidou M, Uphill J, Patel

Y, Hughes JT, Lord J, Turton J, Hartmann AM, Cecchetti R, Fenoglio C, Serpente M,

Arcaro M, Caltagirone C, Orfei MD, Ciaramella A, Pichler S, Mayhaus M, Gu W, Lleo A,

Fortea J, Blesa R, Barber IS, Brookes K, Cupidi C, Maletta RG, Carrell D, Sorbi S,

M, Lawlor B, Lynch A, Fox NC, Hardy J, Albin RL, Apostolova LG, Arnold SE,

EH, Bird TD, Boeve BF, Bowen JD, Boxer A, Burke JR, Burns JM, Buxbaum JD, Cairns 
Hamilton RL, Harrell LE, Honig LS, Huentelman MJ, Hulette CM, Hyman BT, Jarvik 
482

483

484

485

Wu CK, Peters O, Nacmias B, Riemenschneider M, Heun R, Brayne C, Rubinsztein DC, Bras J, Guerreiro R, Al-Chalabi A, Shaw CE, Collinge J, Mann D, Tsolaki M, Clarimon J, Sussams R, Lovestone S, O'Donovan MC, Owen MJ, Behrens TW, Mead S, Goate AM, Uitterlinden AG, Holmes C, Cruchaga C, Ingelsson M, Bennett DA, Powell J, Golde TE, Graff C, De Jager PL, Morgan K, Ertekin-Taner N, Combarros O, Psaty BM, Passmore P, Younkin SG, Berr C, Gudnason V, Rujescu D, Dickson DW, Dartigues JF, DeStefano AL, Ortega-Cubero S, Hakonarson H, Campion D, Boada M, Kauwe JK, Farrer LA, Van Broeckhoven C, Ikram MA, Jones L, Haines JL, Tzourio C, Launer LJ, Escott-Price V, Mayeux R, Deleuze JF, Amin N, Holmans PA, Pericak-Vance MA, Amouyel P, van Duijn CM, Ramirez A, Wang LS, Lambert JC, Seshadri S, Williams J, and Schellenberg GD. 2017. Rare coding variants in PLCG2, ABI3, and TREM2 implicate microglialmediated innate immunity in Alzheimer's disease. Nat Genet 49:1373-1384. Doi: $10.1038 / \mathrm{ng} .3916$

Thrash JC, Torbett BE, and Carson MJ. 2009. Developmental regulation of TREM2 and DAP12 expression in the murine CNS: implications for Nasu-Hakola disease. Neurochem Res 34:38-45. Doi: 10.1007/s11064-008-9657-1

White TE, Ford GD, Surles-Zeigler MC, Gates AS, Laplaca MC, and Ford BD. 2013. Gene expression patterns following unilateral traumatic brain injury reveals a local proinflammatory and remote anti-inflammatory response. BMC Genomics 14:282. Doi: $10.1186 / 1471-2164-14-282$

Willcox DC, Willcox BJ, Hsueh WC, and Suzuki M. 2006. Genetic determinants of exceptional 
503

504

505

506

507

508

509

510

511

512

513

514

515

516

517

518

519

520

521

522

523

human longevity: insights from the Okinawa Centenarian Study. Age (Dordr) 28:313-332. Doi: $10.1007 / \mathrm{s} 11357-006-9020-\mathrm{x}$

Woiciechowsky C, Schoning B, Cobanov J, Lanksch WR, Volk HD, and Docke WD. 2002. Early IL-6 plasma concentrations correlate with severity of brain injury and pneumonia in brain-injured patients. $J$ Trauma 52:339-345.

Xing G, Barry ES, Benford B, Grunberg NE, Li H, Watson WD, and Sharma P. 2013. Impact of repeated stress on traumatic brain injury-induced mitochondrial electron transport chain expression and behavioral responses in rats. Front Neurol 4:196. Doi: 10.3389/fneur.2013.00196

Yiu G, and He Z. 2006. Glial inhibition of CNS axon regeneration. Nat Rev Neurosci 7:617-627. $10.1038 / \mathrm{nrn} 1956$

Zhang C, Wang C, Jia Z, Tong W, Liu D, He C, Huang X, and Xu W. 2017. Differentially expressed mRNAs, lncRNAs, and miRNAs with associated co-expression and ceRNA networks in ankylosing spondylitis. Oncotarget 8:113543-113557. Doi: 10.18632/oncotarget.22708

Zhang L, Ding K, Wang H, Wu Y, and Xu J. 2016. Traumatic Brain Injury-Induced Neuronal Apoptosis is Reduced Through Modulation of PI3K and Autophagy Pathways in Mouse by FTY720. Cell Mol Neurobiol 36:131-142. Doi: 10.1007/s10571-015-0227-1

Zhang YB, Gong JL, Xing TY, Zheng SP, and Ding W. 2013. Autophagy protein p62/SQSTM1 is involved in HAMLET-induced cell death by modulating apotosis in U87MG cells. Cell Death Dis 4:e550. Doi: 10.1038/cddis.2013.77 


\section{Figure Legends}

\section{Figure 1a. Heat map for top 50 DEGs between TBI versus control.}

527 Con: Control group; Exp: TBI group; high-expression genes are marked in red, while low528 expression genes are marked in blue.

529 Figure 1b. Heat map for all DEGs between TBI versus control.

530 Con: Control group; Exp: TBI group.

531 Figure 2. Top 10 most significantly enriched GO terms in the three functional groups 532 (compared with the NC).

\section{Figure 3.15 KEGG pathways of interest in TBI.}

534 The $y$-axis represents the pathway, and the $x$-axis represents the negative logarithm of $P$ value $(-$

$535 \lg P$ ). The higher the value, the smaller the $P$ value, that is, the higher the significance level of the

536 differential gene pathway. The color and size of the bubble represent $-\operatorname{lgP}$ significance and the

537 number of differentially expressed genes enriched in the pathway, respectively.

\section{Figure 4. Signal-net map.}

539 Circles represent genes (red indicates hub genes, while blue indicates the other genes). The size

540 of the circle represents the level of "betweenness centrality." Lines represent interactions

541 between genes.

542 Figure 5. mRNA-TF-Net. 
543 Blue represents mRNAs, red represents top TFs, and yellow represents other TFs.

544 
Figure 1

Figure 1 a. Heat map for top 50 DEGs between TBI versus control. Con: Control group; Exp: TBI group; high-expression genes are marked in red, while low-expression genes are marked in blue. b. Heat map for all DEGs between TBI versus control. Con: Control

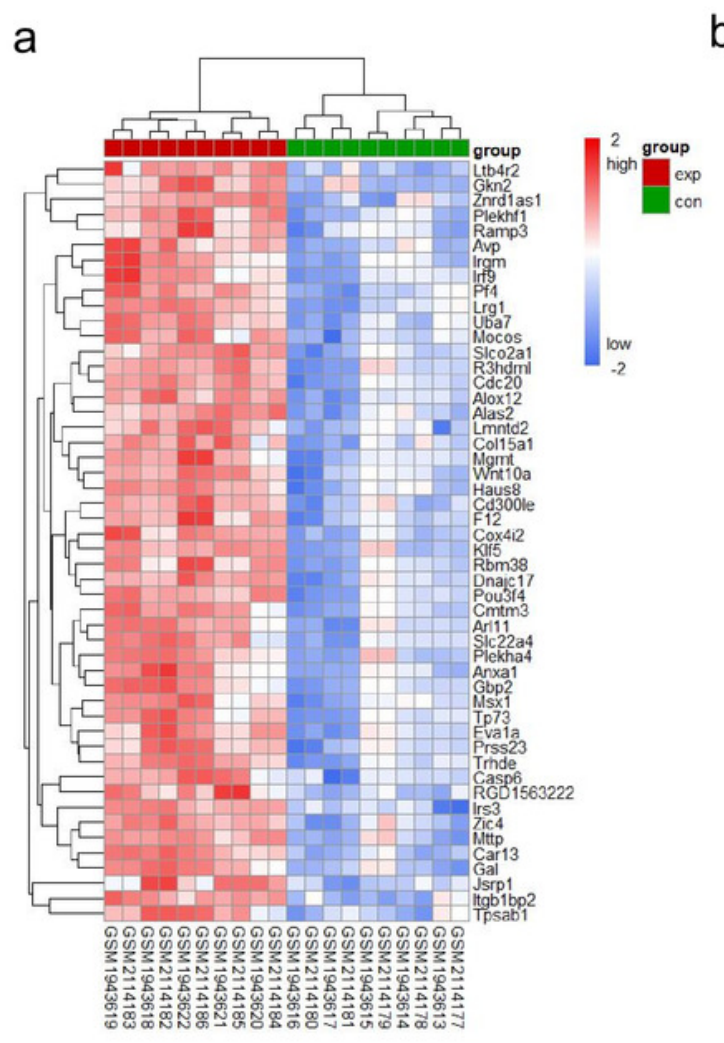

b

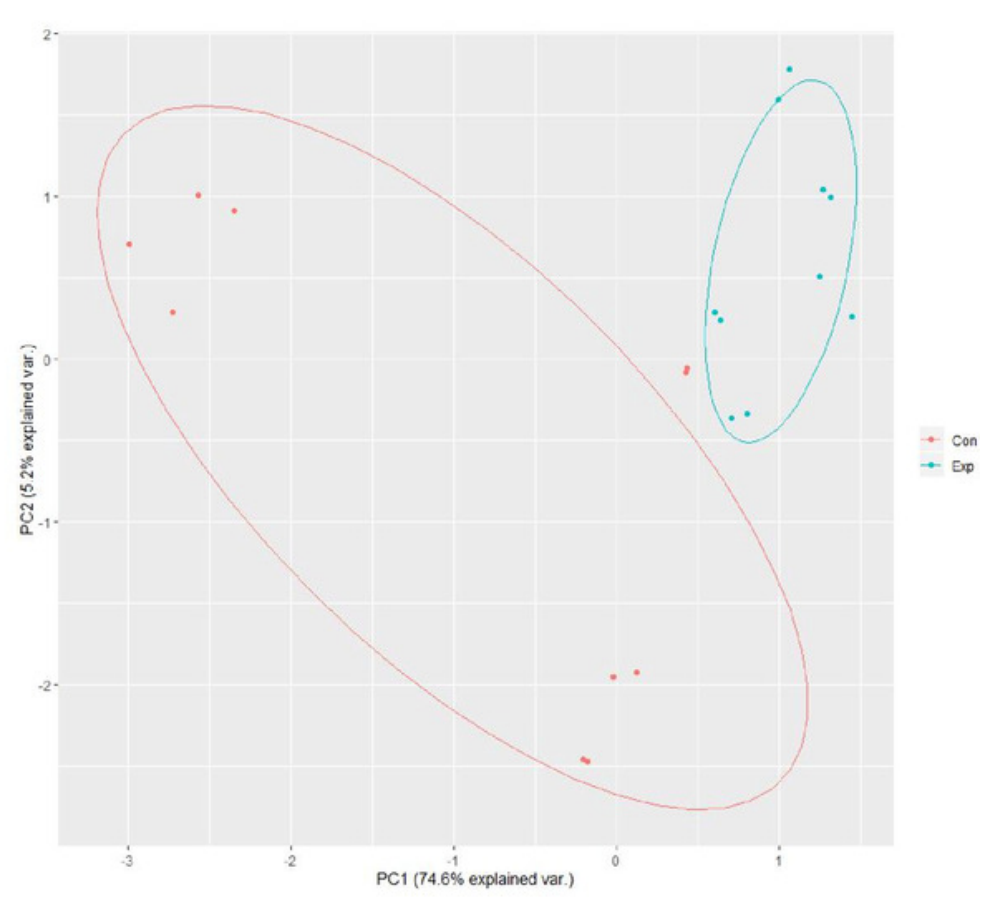




\section{Figure 2}

Top 10 most significantly enriched GO terms in the three functional groups (compared to the NC).

\section{Top 10 most significantly enriched GO terms in the three functional groups (compared to the NC).}

heterocyclic compound binding organic cyclic compound binding -

ion binding -

RNA binding -

catalytic activity -

macromolecular complex binding -

enzyme binding -

nucleic acid binding -

identical protein binding -

anion binding -

nucleus -

cytosol -

intracellular organelle lumen -

organelle lumen -

membrane-enclosed lumen -

nuclear part -

extracellular vesicle -

extracellular exosome -

extracellular organelle -

vesicle -

positive regulation of biological process -

positive regulation of cellular process cellular component organization or biogenesis cellular nitrogen compound metabolic process -

cellular component organization -

organonitrogen compound metabolic process -

gene expression -

cellular protein metabolic process -

cellular biosynthetic process -

negative regulation of biological process -

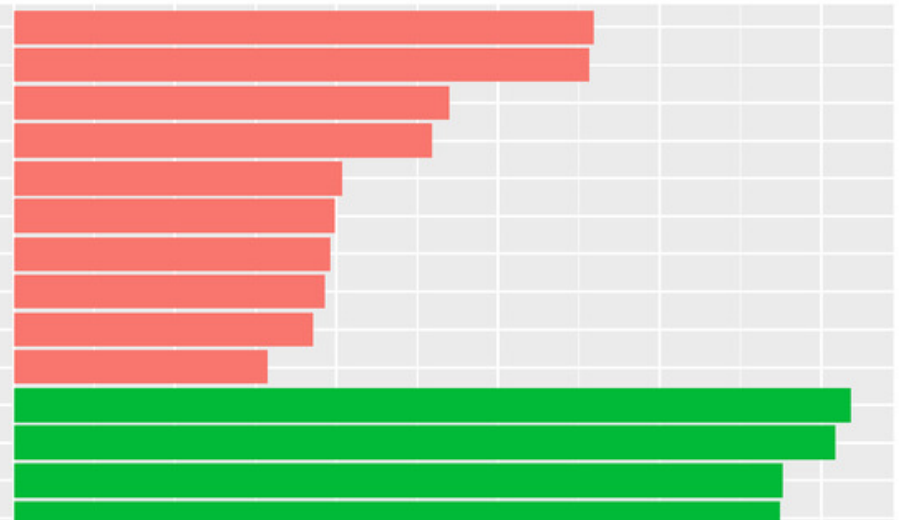

biotype

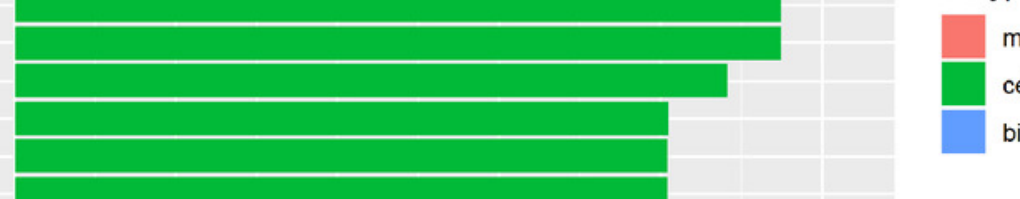

molecular function cellular component biological process 


\section{Figure 3}

\section{KEGG pathways of interests in TBI}

$\mathrm{Y}$-axis represents the pathway and the $\mathrm{X}$-axis represents the negative logarithm of $\mathrm{P}$ value (LgP). The higher the value, the smaller the $P$ value, i.e., the higher the significance level of the differential gene pathway. The color and size of the bubble represents -LgP significance and the number of differentially expressed genes enriched in the pathway, respectively. 


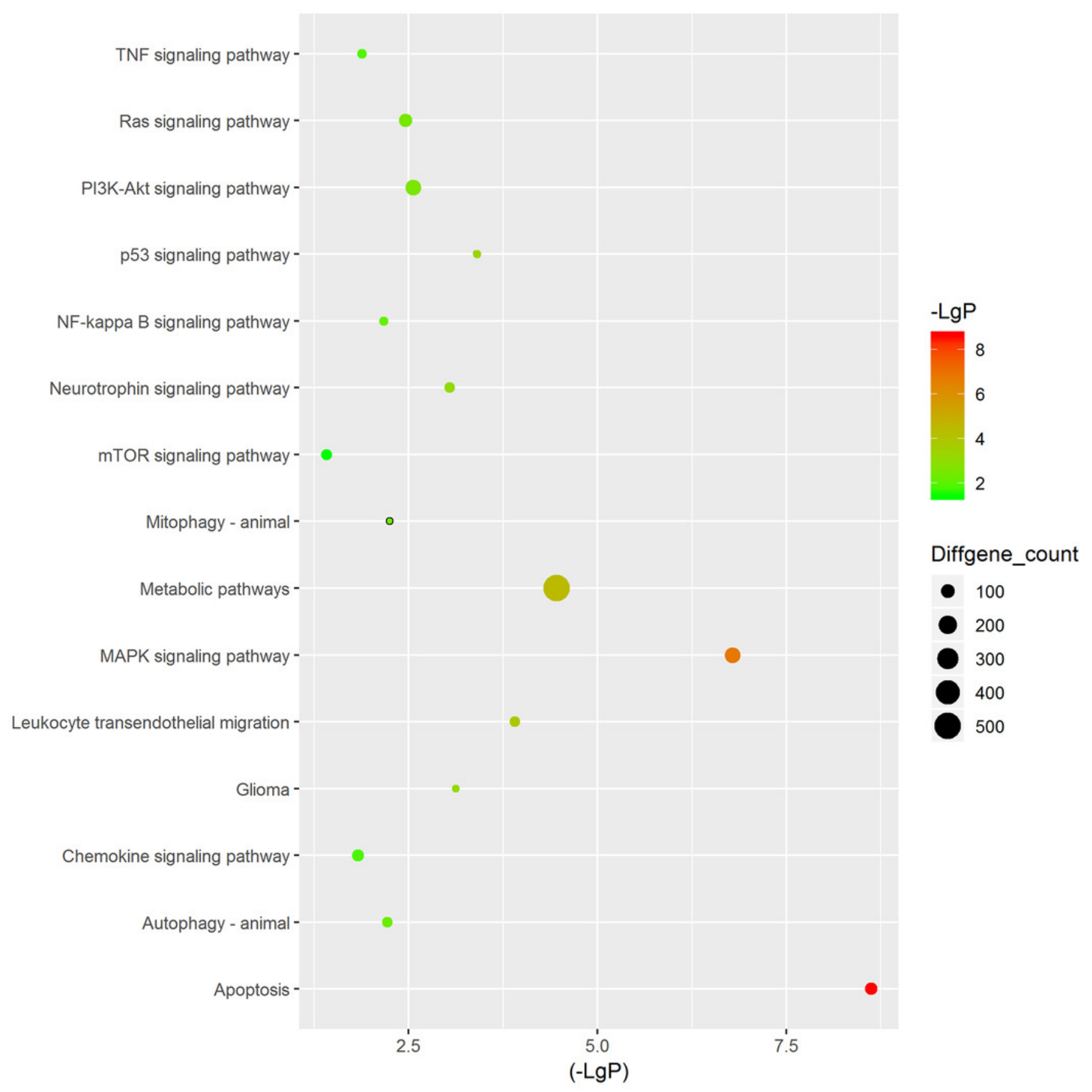


Figure 4

Figure 4. Signal-net map. Circles represent genes (red indicates hub genes, while blue indicates the other genes). The size of the circle represents the level of "betweenness centrality." Lines represent interactions between genes.

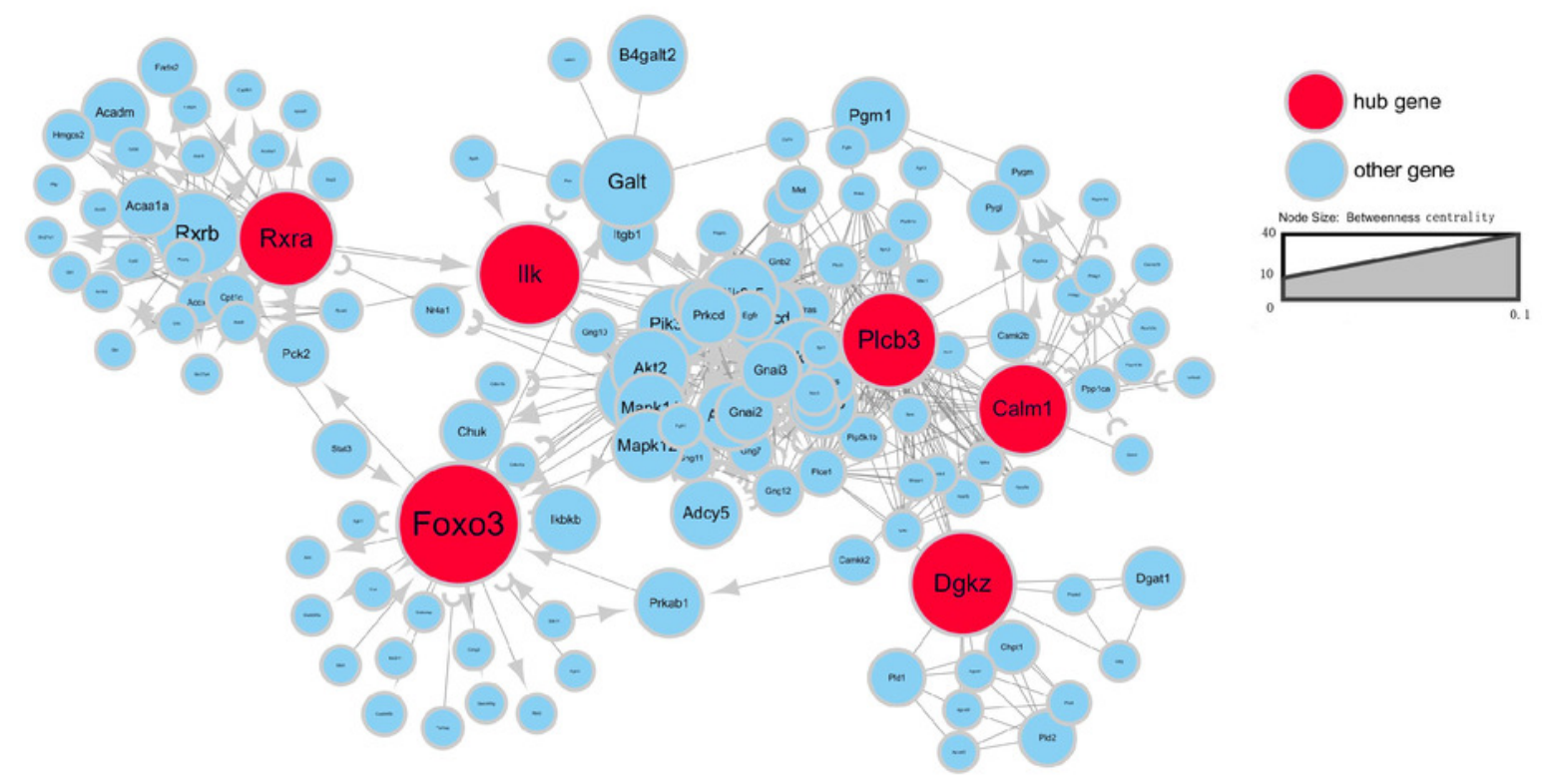




\section{Figure 5}

Figure 5. mRNA-TF-Net. Blue represents mRNAs, red represents top TFs, and yellow represents other TFs.

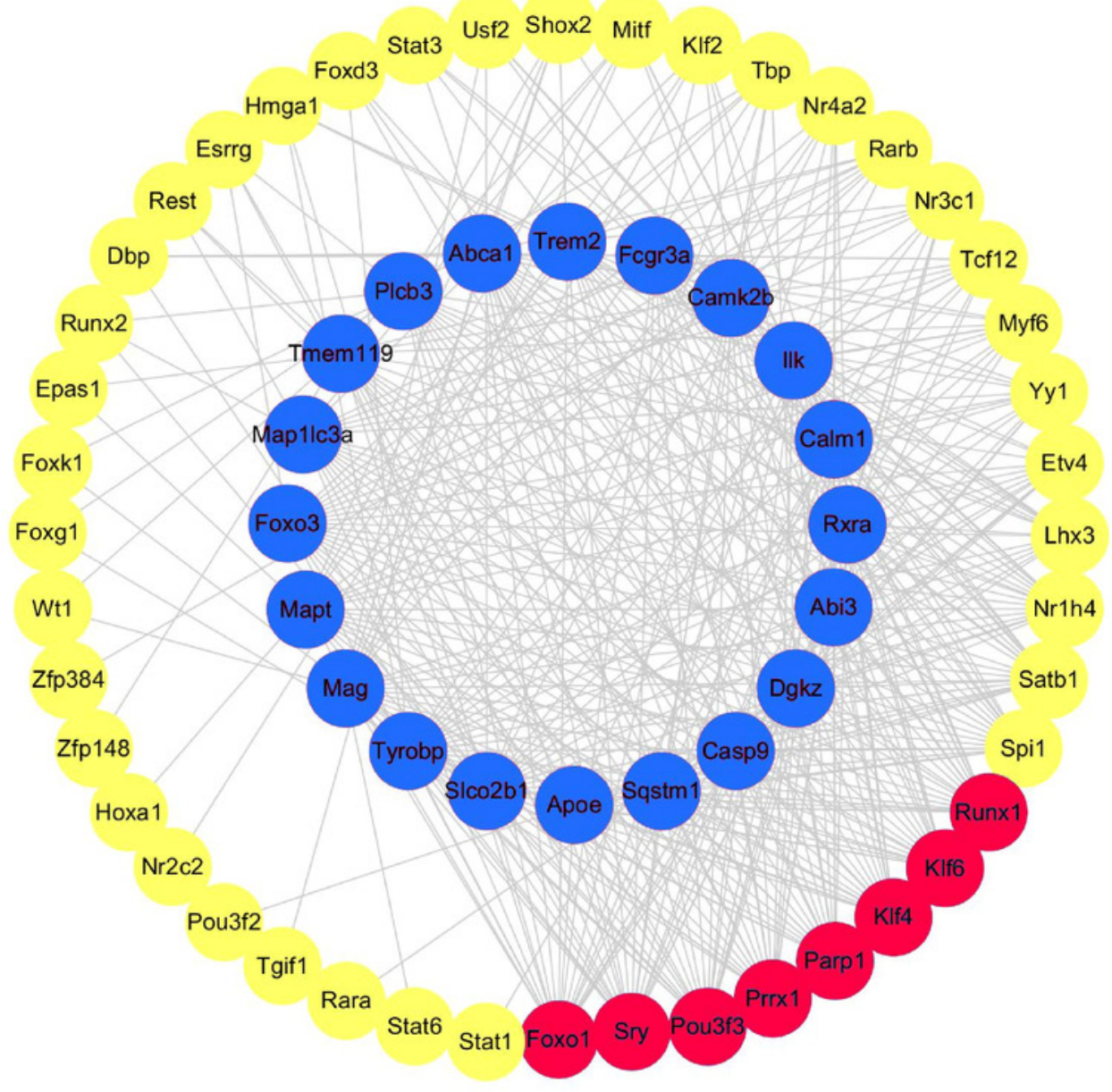


Table $\mathbf{1}$ (on next page)

DEGs (selected) between TBI and NC

DEGs (selected) between TBI and NC 
1 Table 1 DEGs (selected) between TBI and NC.

\begin{tabular}{|c|c|c|c|c|}
\hline Gene symbol & p_values & p_adjust & fold_change (Exp/Con) & style \\
\hline Apoe & 0.000606 & 0.027409 & 1.778066 & up \\
\hline Plcb3 & 0.001583 & 0.029642 & 1.76812 & up \\
\hline Tyrobp & 0.002017 & 0.029917 & 2.243941 & up \\
\hline Dgkz & 0.002115 & 0.030317 & 1.656656 & up \\
\hline Mag & 0.002141 & 0.030421 & 1.608197 & up \\
\hline Abcal & 0.002142 & 0.030421 & 1.704966 & up \\
\hline Ilk & 0.002785 & 0.03094 & 1.410699 & up \\
\hline Trem2 & 0.002807 & 0.031055 & 1.830888 & up \\
\hline Fcgr3a & 0.003078 & 0.031063 & 1.685427 & up \\
\hline Foxo3 & 0.00573 & 0.033484 & 1.514945 & up \\
\hline Abi3 & 0.005796 & 0.033605 & 1.633516 & up \\
\hline Rxra & 0.006317 & 0.034032 & 1.710812 & up \\
\hline Map1lc3a & 0.0075 & 0.035039 & 1.430401 & up \\
\hline P2ry12 & 0.008467 & 0.036137 & 1.60919 & up \\
\hline
\end{tabular}




\begin{tabular}{|c|c|c|c|c|}
\hline Sqstm1 & 0.008739 & 0.036397 & 1.504762 & up \\
\hline Mapt & 0.009304 & 0.037017 & 1.451565 & up \\
\hline Tmem119 & 0.010333 & 0.038487 & 1.756732 & up \\
\hline Slco2b1 & 0.011369 & 0.039789 & 1.614069 & up \\
\hline Calm1 & 0.019664 & 0.048272 & 1.392877 & up \\
\hline Casp9 & 0.01971 & 0.048307 & 1.45513 & up \\
\hline
\end{tabular}


Table 2 (on next page)

KEGG pathway analysis

KEGG pathway analysis 


\section{Table 2 KEGG pathway analysis}

\begin{tabular}{|l|l|l|l|}
\hline Pathway & p-value & Enrichment & overlappin \\
& & Score & Count \\
\hline Apoptosis & $2.36733 \mathrm{E}-09$ & 1.753575 & 79 \\
\hline MAPK signaling pathway & $1.62509 \mathrm{E}-07$ & 1.439707 & 138 \\
\hline Metabolic pathways & $3.50457 \mathrm{E}-05$ & 1.14622 & 501 \\
\hline Leukocyte transendothelial & 0.000123951 & 1.524076 & 56 \\
\hline migration & & & 56 \\
\hline p53 signaling pathway & 0.000392348 & 1.607194 & 38 \\
\hline Glioma & 0.000752699 & 1.58694 & 36 \\
\hline Neurotrophin signaling pathway & 0.00090182 & 1.427188 & 57 \\
\hline PI3K-Akt signaling pathway & 0.002774279 & 1.219635 & 136 \\
\hline Ras signaling pathway & 0.003476288 & 1.26244 & 96 \\
\hline Mitophagy - animal & 0.005672088 & 1.492673 & 31 \\
\hline Autophagy - animal & 0.006088794 & 1.331332 & 57 \\
\hline
\end{tabular}




\begin{tabular}{|l|l|l|l|}
\hline NF-kappa B signaling pathway & 0.006825466 & 1.387437 & 43 \\
\hline Longevity regulating pathway & 0.012090795 & 1.371485 & 39 \\
\hline TNF signaling pathway & 0.013180888 & 1.32523 & 47 \\
\hline Chemokine signaling pathway & 0.014932003 & 1.245003 & 72 \\
\hline NOD-like receptor signaling & 0.019384236 & 1.244378 & 66 \\
\hline pathway & & & \\
\hline
\end{tabular}

2 
Table 3(on next page)

Overlapping genes for neurodegenerative diseases

Overlapping genes for neurodegenerative diseases 
1 Table 3 Overlapping genes for neurodegenerative diseases

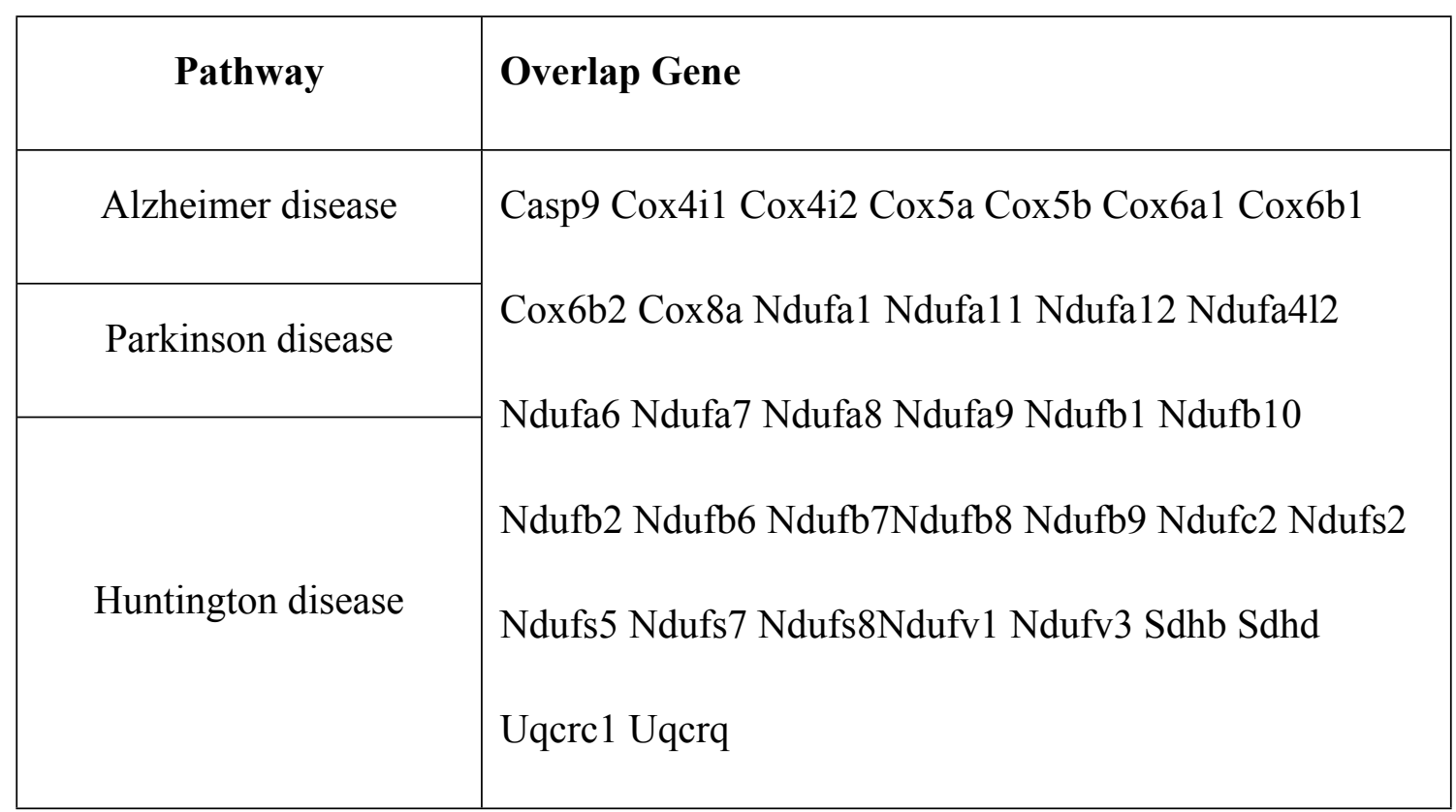

2 